\title{
Boundaries, Continuity, and Contact
}

\author{
Achille C. Varzi \\ Department of Philosophy, Columbia University, New York, NY
}

(Published in Noûs, 31 (1997), 26-58; reprinted in Patrick Grim, Gary Mar, and Kenneth Baynes (eds.), The Philosopher's Annual, Volume 20, Atascadero (CA): Ridgeview, 1999)

\begin{abstract}
There are conflicting intuitions concerning the status of a boundary separating two adjacent entities (or two parts of the same entity). The boundary cannot belong to both things, for adjacency excludes overlap; and it cannot belong to neither, for nothing lies between two adjacent things. Yet how can the dilemma be avoided without assigning the boundary to one or the other thing at random? Some philosophers regard this as a reductio of the very notion of a boundary, which should accordingly be treated a mere façon de parler. In this paper I resist this temptation and examine some ways of taking the puzzle at face value within a realist perspective-treating boundaries as ontologically on a par with (albeit parasitic upon) voluminous parts.
\end{abstract}

\section{Introduction}

The world of everyday experience is mostly a world of physical things separated in various ways from their environment: things with surfaces, skins, crusts, boundaries of some sort. These may not always be sharply defined, or so some would argue. Clouds, for instance, seem to have hazy boundaries, and so do mountains (at least at the root). But, generally speaking, boundaries seem to belong to the palette of basic ontological tools with which we commonly describe the middle-size reality of ordinary experience. Events too have boundaries, at least temporal boundaries. Susan's swim through the Channel began with her dive and ended with her last stroke. Our lives are bounded by our births and our deaths. If one will, intentional entities such as concepts, thoughts, or purposes also have boundaries, though these may be somewhat metaphorical in nature. And, of course, languages have boundaries, and Wittgenstein could emphatically proclaim that the boundaries of our language are the boundaries of our world. 
This general picture is so natural and pervasive that it is hard to deny boundaries a central place in our conceptual scheme. Boundaries are intrinsically connected with whatever entities they bound-in a way boundaries are even more important, since they are the first and primary things with which we seem to be directly acquainted. At the same time, the folk theory of boundaries is far from complete, and indeed several puzzles threaten any attempt to provide a comprehensive and systematic account of this notion. For instance, common sense is unaccustomed to the point-set topological distinction between open and closed entities. But then, how are the spatiotemporal relations between an extended object and its complement to be explained? And how is the relation of contact between contiguous substances to be accounted for? As Leonardo put it in a memorable passage of his Notebooks: "What is it . . that divides the atmosphere from the water?" Shall we assume with him that there must be "a common boundary, which is neither air nor water but is without substance, because a body interposed between two bodies prevents their contact, and this does not happen in water with air"? ${ }^{1}$ Or shall we say, following Brentano, that there are two boundaries, one of air and one of water, which are exactly co-localized in space and time? ${ }^{2}$ Or again, shall we rather accept Bolzano's "monstruous doctrine" that contact is only possible between a body with a surface and another without, so that either water or air (but which?) will be unbounded after all? ${ }^{3}$ Common sense has no straight answer to such questions. Yet there is no point in denying that these are meaningful and indeed very fundamental questions that any common-sense theory of boundaries - or any boundarybased theory of the objects of ordinary experience-must be able to answer.

In recent years this issue has been the focus of considerable debate, both with regard to its cognitive and ontological underpinnings and, perhaps more indirectly, in the context of related research in natural language semantics and spatiotemporal reasoning. Stroll's and Adams' work on surfaces, Chisholm's and Smith's investigations into Brentano's theory of the contin-

1 Leonardo da Vinci (1478/1518), pp. 75-76.

2 See, e.g., Brentano (1976), passim.

3 Bolzano (1851), § 66. The epithet "monstruous doctrine" is Brentano's (1976), p. 146. 
uum, Gibson's ecological psychology, and Jackendoff's work on conceptual semantics are only a few indicative examples. ${ }^{4}$ One of my purposes here is to provide some assessment of this debate, with particular emphasis on its relevance to the analysis of common-sense reasoning about space and time. But my aim is also to try and address the issue somewhat independently, showing how it relates to those theories of space and time where boundaries have actually been banished from the domain of reference. These include, for instance, models of qualitative topology rooted in recent formalizations of Whitehead's theory of extensive connection, and theories of temporal reasoning developed under the impact of Allen's interval calculus. ${ }^{5}$ Although such theories have no room for boundary elements, they do face the same kind of problems illustrated above in boundary-based terminology. How much of the difference is pure terminology and how much is a substantial matter is, I think, an interesting and yet rather unexplored issue, and my purpose in the following is to go a bit further in the direction of an assessment.

\section{The Boundary with Physical Reality}

Let me stress that my concern is only with what I called middle-size reality. Thus, here I am not particularly interested in taking a stand on the issue of whether boundaries really exist, if that is understood on the assumption that physical reality is all the reality there is.

Indeed, it is an obvious and uncontroversial fact that, strictly speaking, ordinary physical objects are not continuous and do not have boundaries of any kind (at least, not boundaries of the sort countenanced by our unre-

4 See, in the given order: Stroll (1979, 1985, 1988); Adams (1973, 1984, 1986, 1996); Chisholm (1984, 1992/93, 1994); Smith (1993, 1995a, 1995b, 1997); Gibson (1966, 1979); Jackendoff (1991). On the historical (and prehistorical) background of the debate, see Zimmerman (1996a).

5 On the former, see Clarke $(1981,1985)$, following Whitehead (1929) and de Laguna (1922). (Recent formal developments include Randell and Cohn (1989), Randell et al. (1992a, 1992b), Aurnague and Vieu (1993), Gotts (1994), Asher and Vieu (1995), Gotts et al. (1996).) On the latter, see Allen (1981, 1984), following Hamblin (1969, 1971). 
flected view of the world). If the solid bodies of common sense are replaced by intricate systems of spatiotemporally indeterminate subatomic particles, speaking of a body's connected boundary is like speaking of the "flat top" of a fakir's bed of nails, to borrow Peter Simons' phrase. ${ }^{6}$ Boundaries become merely imaginary entities enveloping smudgy bunches of hadrons and leptons, and their exact shape and properties involve the same degree of arbitrariness as those of any mathematical graph smoothed out of scattered and inexact data. I take this to be a true story, in some obvious sense. But of course it is a story that can only be appreciated within the framework of a microscopic description of the world-and that is not what I am interested in here. It is not the kind of description we use in our everyday actions. Nor is it the description of the world we need to rely on in order to explain the behavior of cats and dogs or to teach a machine-say, a robot with suitable sensory modules - to move around and interact autonomously with the environment. As J. J. Gibson put it:

There is physical structure on the scale of millimicrons at one extreme and on the scale of light years at another. But surely the appropriate scale for animals is the intermediate one of millimeters to kilometers, and it is appropriate because the world and the animal are then comparable. ${ }^{7}$

It is this intermediate world-whose exact cognitive and ontological status I shall leave open-that I shall be concerned with. It is the same world in which I find it reasonable to talk of holes and shadows as of full-fledged entities, though aware I can be of their ultimate physical unreality. ${ }^{8}$ And in this world, physical objects typically come in finite chunks of continuous matter with closed, continuous spatiotemporal boundaries.

I take a similar stance with respect to the domain of events and eventlike temporal entities. Surely, even if we accept such entities as part of our ontological inventory, one might argue that no instantaneous events really exist, hence no boundaries are ever to be found in the realm of happenings except in some loose sense. Thus, for instance, in a recent article Antony Galton remarks that, in a scientific spirit, a body's being at rest amounts to

6 Simons (1991), p. 91.

7 Gibson (1966), pp. $21 \mathrm{f}$.

8 I have studied holes in joint work with Roberto Casati. See our (1994). 
the fact that the vector sum of the motions of the trillions of restless atoms of which the body is composed, averaged over time, is zero:

The averaging over time makes it impossible to pinpoint, even in principle, an instant at which this condition ceases to obtain. Thus it might be claimed that no real meaning can be attached to the assertion that the body's beginning to move is an instantaneous event. ${ }^{9}$

As Galton points out, however, in the context of qualitative reasoning this objection is beside the point. This is not to insist on the somewhat questionable claim that we do perceive or have experience of events that obtain for only an instant. (Various authors, from Russell to Bill Newton-Smith, have contended precisely the opposite.$^{10}$ ) Rather, the objection is beside the point simply because the notion of two states abutting each other is part of our conceptual scheme, just as the notion of two objects touching each other. And whether or not one countenances instants, if one allows for abutting states, that which happens at their juncture is perfectly describable as the double-barrelled instantaneous event of one state's ending and the other state's beginning to hold.

I do not mean to insist too much on the naive-physical flavor of all this and, as I said, I do not intend to address the issue of the exact cognitive and ontological status of the middle-size world I attribute to common sense. Simply, much of what one can say about boundaries would be meaningless except on the grounds of such caveats. Even if one wishes to stick closer to the ontology of the physical sciences, the fact remains that space and time are most naturally regarded as open-ended continua within which things are free to move and events to occur. Reasoning about the regions of such a spatiotemporal coordinate system (as opposed to the spatiotemporal entities that occupy them) is typically a matter of continuous reasoning. And if talk of boundaries and contact is deemed inadequate with respect to the entities of atomic physics, one still needs it when it comes to the regions of space and time occupied by the putative objects of common sense.

9 Galton (1994), p. 4.

10 Compare e.g. Russell (1914), p. 121; Newton-Smith (1980), p. 135. 


\section{Constraints on Theories}

Boundaries presuppose continuity, then. But continuity is also a source of puzzles for boundaries, as Leonardo's worry indicates. More precisely, we may locate the difficulty in the seeming mutual incompatibility of the following three intuitions:

(a) continuity;

(b) existence of boundaries;

(c) possibility of contact between separate things/regions.

Any attempt to subject the notion of boundary to systematic investigation must explain how the compatibility can be restored, or else give up one or more of (a)-(c).

We just saw that giving up continuity is hardly a solution from the viewpoint of common sense-so (a) should better stay. And I take it that denying (c), the possibility of contact between separate things or regions, is likewise too radical a solution. Even if we go with the standard topological idea that no two closed entities (entities with boundaries of their own) can touch each other, we still need to do justice to the intuition that every entity must at least be in contact with its complement. This is enough to cause problems, as with Peirce's puzzle: Which color is the line of demarcation between a black spot and a white background? ${ }^{11}$ Does the line belong to the spot, or to the background? Likewise, in the temporal realm, the old riddle threatens: At the instant when an object stops moving, is it in motion, or is it at rest? ${ }^{12}$ In both cases, it seems that any way of privileging one answer over the other, hence any way of deciding where the boundary belongs, leaving one entity closed and the other open, would involve a contravention of the principle of sufficient reason. So the burden is really on (b), and the acceptance of boundaries seems the only open assumption.

In view of the remarks of the previous section, I take this to amount to the following alternative. On the one hand, one could say that boundaries are part of the ontology of common sense, but only of the prima facie ontology.

11 Compare Peirce (1893), p. 98.

12 See e.g. Aristotle, Physics, VI, 234a ff. 
Once we subject them to critical analysis we realize that they are a mere $f a$ çon de parler: we don't need them, so to speak; and as we dispense with them, we also get rid of all the problems they carry along. This is a reasonable strategy, but it entails some radical revisions in the semantics of natural language. (As H. H. Price once put it: “'Surface,' it is true, is a substantive in grammar; but it is not the name of a particular existent, but of an attribute." 13 The question then arises of how to account for the meaning of sentences quantifying over or referring to such fictitious particulars.) I call theories that follow this approach "boundary-free" theories, regardless of their specific revisionary content. On the other hand, a truly "boundary-based" theory will have to take the problems at face value, and provide some direct account of both Leonardo's and Peirce's puzzles. This is the strategy I favor, and I shall eventually consider some ways of pursuing it. First, however, I want to argue that the former option is only illusory, and no satisfactory account is to be expected from a boundary-free theory.

\section{Boundaries as Façons de Parler}

The view that boundaries are a mere façon de parler-even for the purpose of qualitative reasoning — can be traced back to Whitehead's theory of extensive connection. This already made its way into the Enquiry, but it is in Process and Reality that we find the most refined formulation of the theory, also thanks to an influential paper by Theodore de Laguna. ${ }^{14}$ More recently, the approach was fully worked out by Bowman Clarke, and it is this recent formulation that I shall consider here. ${ }^{15}$

We may see two parts of the theory, both of which are significant for our purposes. On the one hand, the theory purports to provide an account of the fundamental relations of contact and, more generally, connection: an ac-

\footnotetext{
13 Price (1932), p. 106.

14 See Whitehead $(1919,1929)$ and de Laguna (1922) respectively. The method was first presented by Whitehead in (1916).

15 Clarke (1981, 1985). See also Randell and Cohn (1989) and Biacino and Gerla (1991). One should also mention here, in the temporal realm, the works of Hamblin and Allen cited in note 5 . I shall stick to the spatial case for simplicity.
} 
count of (c) above in the presence of (a), but without requiring (b). On the other hand, the theory also aims to provide an indirect account of such notions as "point," "line," "surface" in such a way as to do justice to their customary geometrical properties. That is, boundary elements are not among the primary entities, but they are nonetheless retrieved as higher-order entities (which explains in what sense they are façons de parler). As C. D. Broad explicitly put it: "It does not in the least matter to science what is the inner nature of a term, provided it will do the work that is required of it." 16 This is achieved through Whitehead's method of "extensive abstraction," which effectively treats boundaries as classes of nested objects that "converge" (though not to an object proper), and which is also symptomatically reflected in the title of de Laguna's paper, "Point, Line, and Surface, as Sets of Solids."

Concerning this second part, I have indeed little to say. If the theory works, if the relevant notions are construed in such a way as to "do the work," then fine-a necessary condition for the eliminativist account is met. One must be aware of the price, though. For such a theory will fall short of ascribing boundary elements one of the fundamental properties they have in the common-sense picture of reality: they are not abstract-not all of them at least (one might argue that the Equator is abstract, but not the surface of the Earth $\left.{ }^{17}\right)$. At any rate, they are not abstract in the sense in which sets are abstract. One can paint the surface of a table, and one can even paint an infinite series of ever thinner layers of table-parts. But one cannot paint the set of these parts (unless of course this is simply another way of saying that the parts are painted).

If one wants to go boundary-free, then, one must honestly carry all the burden of the choice of making sense of all boundary-talk without assuming boundaries, regardless of whether one can then reconstruct these as second or perhaps even higher-order entities in the spirit of Broad's maxim. You

16 Broad (1923), p. 39.

17 Some authors, most notably Stroll (1988), have argued that every boundary can be viewed either as an abstraction or as a physical feature, and that this conceptual vacillation cannot be resolved. I shall not pursue this hypothesis here, though I shall eventually consider a way of dealing with the opposition (Sections 8-9) and with the possibility of treating 'boundary' as a context-dependent concept (Section 10a) 
can only paint the table — so forget the surface. This, by the way, applies not only to Whitehead's (Clarke's) account, but also to other techniques for recovering the notion of unextended boundaries in terms of extended entities, whatever their ultimate underlying motivations. ${ }^{18}$ There is undoubtedly some appeal in the idea that the notion of a boundary involves some sort of abstraction. But it is hard to find satisfaction in the idea that this abstraction is to be explained in terms of the abstractness of set-theoretic constructions. (I am thinking here of geometric accounts. An "operationalist" account of the sort advocated by Ernest Adams, for instance, where the abstractive process by which boundary elements are derived from concrete observables is explained in terms of "operational tests," arguably eschews this line of objection. ${ }^{19}$ But I should think that such an account may be regarded as a parallel story, one which offers an explanation of empirical knowledge concerning boundaries while remaining ultimately neutral with regard to the their ontological status.)

Let us then focus on the first part of the theory-the theory of the connection relation. Clarke's formulation is well known by now, so I will only review it briefly. It takes connection as a primitive relation (in effect, as the only primitive) and it interprets this relation as holding between regions that share at least some common spatiotemporal point. (Thus, the theory proceeds from the supposition that spatiotemporal reasoning about things and events can be reduced to reasoning about their spatiotemporal receptacles.) This was also Whitehead's suggested interpretation. It follows that connection, which I shall symbolize by ' $C$ ', must be axiomatized as reflexive and symmetric:

$$
\begin{aligned}
& \mathrm{C}(x, x) \\
& \mathrm{C}(x, y) \rightarrow \mathrm{C}(y, x) .
\end{aligned}
$$

18 Besides de Laguna's cited work and Broad's own account in (1923), major examples include the constructions of Nicod (1924), Russell (1927), Tarski (1929), and Menger (1940). (See Gerla (1995) for an up-to-date overview, and Forrest (1996) for a recent variant.) The approach has well-known analogues in the temporal realm, where instants are sometimes construed as sets of time intervals (which in turn are sometimes construed as sets of overlapping events). The locus classicus is Russell's construction in (1914), echoed in Walker (1947) and Kamp (1979).

19 See Adams (1996) for a recent formulation. 
In addition, $C$ is assumed to be extensional:

$$
\forall z(\mathrm{C}(z, x) \leftrightarrow \mathrm{C}(z, y)) \rightarrow x=y,
$$

which induces a definition of parthood ('P') along the following lines:

$$
\mathrm{P}(x, y)=_{\mathrm{df}} \forall z(\mathrm{C}(z, x) \rightarrow \mathrm{C}(z, y)) .
$$

This allows Whitehead and Clarke to reconstruct various mereological notions in terms of the topological primitive, though the resulting mereology need not be quite standard. Elsewhere I have argued that (4) is actually too restrictive as a general definition, at least if our purpose is indeed to talk not only about spatiotemporal regions but also about their natural occupants (i.e., material bodies and events). ${ }^{20}$ Here however I shall for the moment leave this issue on a side and focus mainly on the topological part. What account of contact do we get in this theory?

Since points are not regions, and since regions are the only entities in the domain (the only receptacles), sharing a point does not imply mereological overlapping, which therefore is only a proper subrelation of connection. Thus, two regions may be connected because they overlap (' $O$ ') or simply because they are externally connected ('EC'):

$$
\begin{aligned}
& \mathrm{O}(x, y)={ }_{\mathrm{df}} \exists z(\mathrm{P}(z, x) \wedge \mathrm{P}(z, y)) \\
& \mathrm{EC}(x, y)=_{\mathrm{df}} \mathrm{C}(x, y) \wedge \neg \mathrm{O}(x, y) .
\end{aligned}
$$

In Clarke's own words, this distinction "constitutes the virtue" of the system. ${ }^{21}$ External connection captures the relation of two regions just "touching" each other, and it gives one the power to distinguish between tangential and internal (non-tangential) parts of any given region-a distinction which runs afoul of purely mereological systems: ${ }^{22}$

$$
\operatorname{TP}(x, y)=_{\mathrm{df}} \mathrm{P}(x, y) \wedge \exists z(\mathrm{EC}(z, x) \wedge \mathrm{EC}(z, y))
$$

20 See Varzi (1994), especially pp. 432-33. The point is further developed in Casati and Varzi (1995, 1996, 1997).

21 Clarke (1981), p. 206. Compare Whitehead (1929), p. 453.

22 Whitehead tried to define them in (1919), but his account was unsuccessful. I discuss this in Varzi (1994), § 2. 


$$
\mathrm{IP}(x, y)=_{\mathrm{df}} \mathrm{P}(x, y) \wedge \neg \mathrm{TP}(x, y) .
$$

Moreover, we may consider adding a general sum or fusion functor picking out, for each satisfied property $\phi$, the sum or fusion of all things connected with some фer:

$$
\sigma x(\phi x)=_{\mathrm{df}} \imath x \forall y(\mathrm{C}(y, x) \leftrightarrow \exists z(\phi z \wedge \mathrm{C}(z, y))) .
$$

This makes it possible to introduce a variety of quasi-topological operators and it paves the way to the prospect that a remarkable amount of topological reasoning may actually be reflected under these conditions and with such a modicum of assumptions:

$$
\begin{aligned}
& \sim x \quad=_{\mathrm{df}} \sigma z(\neg \mathrm{C}(z, x)) \quad \text { (complement) } \\
& \mathrm{i}(x)={ }_{\mathrm{df}} \sigma z(\operatorname{IP}(z, x)) \quad \text { (interior) } \\
& \mathrm{e}(x)={ }_{\mathrm{df}} \sigma z(\operatorname{IP}(z, \sim x)) \quad \text { (exterior) } \\
& \text { (13) } \mathrm{C}(x)={ }_{\mathrm{df}} \sigma z(\neg \mathrm{C}(z, \mathrm{i}(\sim x))) . \quad \text { (closure) }
\end{aligned}
$$

(These operators are quasi-topological due to the absence of an axiom guaranteeing the existence of the null region, in conformity with the classical formulations of extensional mereology.)

In fact, nothing would prevent us here from also introducing an explicit boundary operator, in perfect agreement with standard topological treatments. ${ }^{23}$ We have several equivalent options-for instance:

$$
\begin{aligned}
& \mathrm{b}(x)={ }_{\mathrm{df}} \mathrm{c}(x) \times \mathrm{c}(\sim x) \\
& \mathrm{b}(x)={ }_{\mathrm{df}} \sim(\mathrm{i}(x)+\mathrm{i}(\sim x)) \\
& \mathrm{b}(x)={ }_{\mathrm{df}} \sim \mathrm{e}(x)-\mathrm{e}(\sim x),
\end{aligned}
$$

where ' $x$ ', ' + ', and '-', are the usual quasi-Boolean operators of mereological product, sum, and difference, respectively:

$x \times y=\mathrm{df} \sigma z(\mathrm{P}(z, x) \wedge \mathrm{P}(z, y))$

(19) $\quad x-y==_{\mathrm{df}} \sigma z(\mathrm{P}(z, x) \wedge \neg \mathrm{O}(z, y))$.

23 Randell and Cohn (1989), p. 361, actually adopt a version of (14), later rejected. 
Such definitions are not unproblematic, due to the peculiar behavior of the complement operator ' ', and I shall come back to this shortly. First, however, let me make clear that anything along the lines of (14)-(16) is in fact ruled out by means of an explicit axiom to the effect that everything has an interior:

(20) $\exists z(\mathrm{IP}(z, x))$.

Obviously, this makes the above definitions ineffective in that $\mathrm{b}(x)$ would always be undefined, and there is therefore no point in introducing the $b$ operator. (To be sure, the exact status of undefined terms in the theory depends on the underlying semantics for the definite description operator ' $l$ '. One might want to say that even though (20) implies that no boundaries exist, nonetheless (14)-(16) provide a definition of the concept, and therefore the system is not entirely boundary-free. This is an interesting issue, but addressing it here would take us too far afield.)

This being the general picture, I have essentially two objections to it, both of which I find conclusive enough to suggest abandoning this route. The first objection is that although the theory has no room for boundaries, it does have room for the standard topological distinction between open and closed entities. The usual definitions apply:

$$
\begin{aligned}
& \mathrm{Cl}(x)={ }_{\mathrm{df}} x=\mathrm{c}(x) \\
& \mathrm{Op}(x)={ }_{\mathrm{df}} x=\mathrm{i}(x) .
\end{aligned}
$$

Now there is nothing wrong with this per se, except that it becomes very difficult to make good sense of the distinction. As Simons put it:

\footnotetext{
What we are being asked to believe is that there are two kinds of individuals, "soft" (open) ones, which touch nothing, and partly or wholly "hard" ones, which touch something. Yet we are not allowed to believe that there are any individuals which make up the difference. We can discriminate individuals which differ by as little as a point, but are unable to discriminate the point. ${ }^{24}$
}

In other words, an open region is always a proper part of its own closure, but there is no mereological difference between the two. This means that if

\footnotetext{
24 Simons (1987), p. 98.
} 
you cut something in half, take the interiors of the two halves (two proper parts thereof), and put them together, you get the whole thing back: you have left out nothing. In short, the "remainder" principle

$$
\neg \mathrm{P}(x, y) \rightarrow \exists z(\mathrm{P}(z, x) \wedge \neg \mathrm{O}(z, y)),
$$

which is a cornerstone of classical extensional mereology as well as of extensional part-whole theories of much lesser strength (e.g., where the fusion operator applies only on strict conditions so as to rule out scattered or otherwise ill-assorted individuals ${ }^{25}$ ), fails.

It is indeed hard to find satisfaction in this picture. Formally, what it amounts to is that the preclusion of boundaries from the domain of interpretation gives rise to a non-standard mereology. (It can be shown that this is exactly equivalent to the subtheory that can be obtained from classical extensional mereology by uniformly restricting all quantifiers by a monadic predicate ${ }^{26}$ ). This is not at all surprising, and one may well argue that it is the price one has to pay on this account: if some elements are removed from the domain, the remainder principle cannot generally hold. But the problem is that the resulting account of contact is heavily affected by this. For if we cannot pinpoint anything that explains the difference between things that touch and things that don't, then we can hardly say we have a notion of what it means for two things (regions) to touch each other.

This ties in with the second objection. I take it that any theory of connection must be capable of explaining, not only the difference between partaking (mereological) versus external (purely topological) connection, but also the difference between what may be called "weak" versus "strong" connection, or, in other terms, contiguity versus continuity. Think of two spheres just touching each other (for simplicity, think of these as two spherical regions, connected to each other in the precise sense of sharing exactly one point): the way they are connected is qualitatively different from the way two halves of a single sphere are connected. In the first case (contiguity), one can go from any one part of one sphere to any part of the other

25 Two interesting examples are Bostock (1979) and Chisholm (1992/93).

26 This result is essentially due to Eschenbach and Heydrich (1995). See Varzi (1996a), §6, for a more extensive account. 
without ever going through the exterior of the whole: this is what makes them connected. In the second case (continuity), one can go from any one part of one half to any part of the other half without ever leaving the interior. The relevant difference could easily be expressed in terms of classical topological notions. We could first of all distinguish between the connectedness ('Cn') of a whole and the connectedness of its interior, or strong connectedness ('SCn'):

$$
\begin{aligned}
& \mathrm{Cn}(x)={ }_{\mathrm{df}} \forall y \forall z(y+z=x \rightarrow \mathrm{C}(y, z)) \\
& \operatorname{SCn}(x)==_{\mathrm{df}} \operatorname{Cn}(\mathrm{i}(x)) .
\end{aligned}
$$

Thus, something is (strongly) connected if and only if it(s interior) does not add up to two disconnected parts. Then we could define strong connection ('SC') as the relation holding between two items when their sum is strongly connected-more generally, when some parts of theirs add up to a strongly connected sum:

$$
\mathrm{SC}(x, y)={ }_{\mathrm{df}} \exists w \exists z(\mathrm{P}(w, x) \wedge \mathrm{P}(z, y) \wedge \mathrm{SCn}(w+z)) .
$$

This relation would have the desired characteristics: it would hold between two halves of a single sphere, but not between two spheres that are in contact. Accordingly, SC would imply C, but not vice versa, and we could say with Aristotle that "the continuous is a species of the contiguous." 27 All of this would be quite sensible in a classical, boundary-based topological framework insofar as connection would only hold between an open and a closed entity. ${ }^{28}$ But here? Here we cannot have one half open and the other closed, because there would be no grounds for saying which is what, and that would be much worse than the classic form of Peirce's puzzle (which remains a problem for the standard topological account). We cannot say that both halves are open either, for in that case they would not even connect. (Open regions can connect only if they overlap.) So they must be both closed. But then, if the two halves of a single sphere are both closed, we have no means of distinguishing their way of being connected from the way

27 Metaphysics, 1069a.

28 This Bolzanian feature is exploited in Smith (1993). I followed it in Varzi (1996b) and Pianesi and Varzi (1994, 1996a, 1996b). (I come back to it below.) 
the two spheres are connected. Hence, the desired distinction is lost, and we have a case of explanatory deficiency in the theory.

It bears emphasis that this is not simply a matter of changing the relevant definitions. Indeed (24) must be emended if there are no boundary elements. For otherwise the theory would force the universe to be disconnected: as was seen above, the failing of (23) implies that the universe can be split into two externally connected parts, the interiors of which are disconnected and yet add up to the whole by (3). One way of avoiding this consequence is to redefine connectedness in terms of connection of the closures of the parts: ${ }^{29}$

$$
\mathrm{Cn}(x)=\mathrm{df}_{\mathrm{df}} \forall y \forall z(y+z=x \rightarrow \mathrm{C}(\mathrm{c}(y), \mathrm{c}(z))) .
$$

This would guarantee that "connectedness" receives its ordinary meaning also in the Whitehead-Clarke theory. Yet such a revision would have no effect on the distinction between weak and strong contact.

\section{A Variant Treatment}

There is a third feature of the theory that one may find unpalatable, namely that every region turns out to be disconnected from its complement. This is an immediate consequence of (10), but would partly hold even if we employed a more standard definition of ' $\sim$ ' in terms of ' $O$ ':

$$
\sim x=_{\mathrm{df}} \sigma z(\neg \mathrm{O}(z, x)) .
$$

In that case, it would follow that a region is connected with its complement only if it is closed, giving rise to the embarrassing question of what separates an open entity from its complement (let alone the question of how two entities_-an open region and its closure_-could have the same complement).

A variant of the theory where this difficulty is overcome has recently been proposed by Tony Cohn and his associates in a series of influential papers, ${ }^{30}$ where the following definition is used instead:

29 This strategy is followed in Asher and Vieu (1995).

30 The first formulations are in Randell et al. (1992a, 1992b). 


$$
\text { (29) } \sim x==_{\mathrm{df}} \mathrm{l} y \forall z((\mathrm{O}(z, y) \leftrightarrow \neg \mathrm{P}(z, x)) \wedge(\mathrm{C}(z, y) \leftrightarrow \neg \mathrm{P}(z, x) \vee \mathrm{P}(x, z))) .
$$

With some effort, this boils down to the intuition that the complement is discrete from every part of the object (region) and disconnected from every interior proper part. This guarantees that every non-universal region be connected (in effect, externally connected) with its own complement. But this apparently minor change-which intuitively reflects a weaker interpretation of ' $\mathrm{C}(x, y)$ ' as meaning that "the topological closures of regions $x$ and $y$ share a common point"- has other major consequences too. For, on the one hand, it avoids the first above-mentioned objection to Clarke's original formulation: the "remainder principle" (23) is now a theorem. On the other hand, (29) also implies a dissolution of the distinction between open and closed regions. This follows from the fact that $\mathrm{O}$ becomes an extensional relation, i.e., the following is now provable:

$$
x=y \leftrightarrow \forall z(\mathrm{O}(z, x) \leftrightarrow \mathrm{O}(z, y)) .
$$

Thus, it is not possible for two items to share exactly the same parts without having the same relationships in terms of connection, and in the presence of (20) (the axiom that everything has interior parts) this deprives the open/ closed distinction of any foundation. The motivations adduced by the authors in support of this change are instructive, as they reflect precisely the reason why one would want to go boundary-free in the first place:

From the naive point of view, the distinction between open, semi-open and closed regions is not drawn. . . . Moreover, . . . if we map bodies to closed regions (as the spaces they occupy), then their complements become open, which is a less agreeable result. An elegant solution to this problem becomes less likely once we allow bodies to break up into parts, since one is left with the result that one part will map to a closed region, and the other to a semi-open region! ${ }^{31}$

There are some minor drawbacks to be noted. For instance, the resulting theory does not support models with atomic regions. (These would have the property that anything connected with them would also be connected with their complement, and by (4) that would vacuously imply the absurdity

31 Randell et al. (1992a), pp. 394-95; compare (1992b), p. 166. 
that every atomic region is part of its complement. ${ }^{32}$ ) Perhaps this is not implausible, but it seems awkward that the atomlessness of space should be a direct corollary of this part of the theory. In any case, this and similar shortcomings depend crucially on the idea of defining $P$ in terms of $C$, and may therefore be put to one side in view of the availability of different strategies for combining mereology and topology. 33

There is also a major drawback, though. For the presence of theorems such as (23) and (30) now makes it hard to makesense of certain distinctions that the theory nonetheless allows. For example, although the authors do not do so, nothing prevents us from introducing the interior and closure operators as in (11) and (13). These are of course redundant, in that the identities

$$
x=\mathrm{i}(x)=\mathrm{c}(x)
$$

always hold by $(23)+(30)$. But since every region is connected with its complement, this amounts to saying that the sum of the interior parts of any region is in contact with the complement of that region-which runs against any pre-theoretical intuition concerning "sum" and "interior part." How can anything made up of interior parts be in contact with the exterior? This is clearly impossible if the number of interior parts is finite; but it sounds paradoxical even in an atomless, infinitely divisible domain. Likewise, since (the closure of) any region includes the sum of the region's tangential parts, (31) says that by putting together the interior parts of any region we eventually get all of its tangential parts - and this, again, goes against the purported intuitive content of these notions. One way or the other, a conceptual incongruity threatens here.

Cohn, Randell, and Cui note this outcome in one of their papers and conclude that the theory must therefore be subjected to "an important metatheoretic restriction concerning Boolean sums or unions of regions, namely that infinite unions cannot be allowed." 34 If we don't allow for infinite

32 This is noted in Randell et al. (1992b), p. 173, correcting a mistake of Randell et al. (1992a). Three alternative ways of dealing with atoms are made available, but they all determine some radical departure from the basic framework.

33 For a discussion of some of these strategies I refer to Varzi (1994, 1996a).

34 Randell et al. (1992b), p. 172. This is a further departure from Clarke's original version of the theory (though not from Whitehead's), which has unrestricted sums. 
sums, we cannot define $\mathrm{i}(x)$ or $\mathrm{c}(x)$, hence the troubles are over. But, of course, this is quite peculiar. Why should the sum principle be called into question here? Why should the mereology suffer from a topological desease? More simply, why should the metatheory be invoked at all? Besides, there is some ambiguity in the notion of allowing for restricted sum formation. The notion is not unfamiliar, of course, the usual motivation being that the unrestricted sum principle has counter-intuitive instances when the sums involve widely scattered, disparate, or otherwise ill-assorted entities, such as the totality of all cats, or Brutus' birth and his stabbing of Caesar. ${ }^{35}$ However, such an objection is based on a misconception. As David Lewis put it, if you already have some things, allowing for their sum is no further commitment: "the fusion is nothing over and above the [things] that compose it. It just is them. They just are it." 36 So we cannot just solve the problem by ruling out sums of interior parts. For the interior parts are all there already - their sum is no further thing (except in the eyes of the quantifiers). Even if the "composition as identity" thesis is withheld, ${ }^{37}$ it is hard to see any reason why these fusions should be proscribed-except for their responsibility in unveiling the limits of the no-boundary axiom (20).

It is then barely necessary to point out that, in spite of this price, the theory does not fare any better than the old one with respect to the distinction between continuity and contiguity. Once the open-closed opposition is gone, the difference between connection and strong connection vanishes and there is no way to capture the desired distinction, except perhaps by introducing some radical changes in the framework. I therefore conclude that although the modified theory copes better than Clarke's in a number of important respects, some basic questions remain essentially unanswered.

\section{Introducing Boundaries}

At this point, let us move on to consider the second strategy mentioned above, viz., the view that boundaries are indeed to be included in our critical

\footnotetext{
35 See e.g. the early criticisms of Lowe (1953) and Rescher (1955).

36 Lewis (1991), p. 81. The locus classicus is of course Goodman (1956).

37 As van Inwagen (1987) has urged (see especially pp. 40-45).
} 
ontology in spite of the apparent incompatibility with either continuity or the possibility of contact. The first way of checking this strategy is simply to see what happens if we drop (20), i.e., the axiom to the effect that everything has interior parts, from the boundary-free mereotopological theories considered above.

To that end, note first of all that we must use caution in choosing the relevant notion of complement. For if we use Clarke's definition (10), we get the absurdity that an entity is in contact with its own boundary if and only if it includes it-i.e., if and only if it is closed, which means that an open entity is forced to be disconnected from its own boundary. (I'm supposing here that boundaries can be defined along the lines of (14)-(16).) So we need a better notion. As I see it, we can either use the refined definition (29), or we can stick to the more standard (24), but with the sum operator ' $\sigma$ ' defined in purely mereological terms, as in classical extensional mereology:

$$
\sigma x(\phi x)={ }_{\mathrm{df}} \imath x \forall y(\mathrm{O}(y, x) \leftrightarrow \exists z(\phi z \wedge \mathrm{O}(z, y))) .
$$

The difference is marginal, in that the former guarantees that everything is connected to its own boundary (whether or not it includes it), while the latter leaves that open, deferring the issue to the axiomatization of the boundary operator (see below). For definiteness, I shall follow the second course. If anything, this has some advantages in terms of conceptual simplicity. But I also prefer this option because I think it is important to keep mereology and topology as clearly separate as possible. In fact, in the following I shall also avoid using (4) as a definition of parthood in terms of connection, assuming ' $P$ ' and ' $C$ ' as two independent primitives instead. (The former will be at least an extensional partial ordering; the latter at least a symmetric and reflexive relation.) The reason for this, as I already mentioned, is that (4) is problematic as a general definition. Thus, only one direction of the corresponding equivalence will be assumed to hold:

$$
\mathrm{P}(x, y) \rightarrow \forall z(\mathrm{C}(z, x) \rightarrow \mathrm{C}(z, y)) .
$$

If one will, one can always assume the other direction as an axiom, but I shall avoid that here.

With these provisos, we are now free to drop (20) and to introduce boundaries explicitly using any of the definitions in (14)-(16) (with ' $\sigma$ ' in- 
terpreted as in (32); I shall henceforth assume this qualification whenever appropriate). We also have some other options, including some that may be more illuminating. I mention two, both of which exploit the idea of defining the boundary operator ' $b$ ' in terms of a more general boundary relation ' $\mathrm{B}$ ':

$$
\mathrm{b}(x)={ }_{\mathrm{df}} \sigma z(\mathrm{~B}(z, x)) .
$$

(Intuitively this relation, B, is to be interpreted as holding whenever the first argument is $a$ boundary of the second, though not necessarily the boundary of it.) The first option exploits the idea that an entity's boundaries-in the sense of B-must be either part of the entity or part of its complement. This can be made precise by defining explicitly the notion of a boundary part ('BP') as a limit case of tangential part:

$$
\begin{aligned}
& \mathrm{BP}(x, y)=_{\mathrm{df}} \forall z(\mathrm{P}(z, x) \rightarrow \mathrm{TP}(z, y)) \\
& \mathrm{B}(x, y)={ }_{\mathrm{df}} \mathrm{BP}(x, y) \vee \operatorname{BP}(x, \sim y) .
\end{aligned}
$$

The second option is perhaps more intuitive. ${ }^{38}$ Say that $x$ straddles $y$ if everything that includes $x$ in the interior overlaps both $y$ and $y$ 's complement; then we can define a boundary of an item $y$ to be any item $x$ all parts of which straddle $y$ :

$$
\begin{aligned}
& \mathrm{S}(x, y)=_{\mathrm{df}} \forall z(\mathrm{IP}(x, z) \rightarrow(\mathrm{O}(z, y) \wedge \mathrm{O}(z, \sim y))) \\
& \mathrm{B}(x, y)=_{\mathrm{df}} \forall z(\mathrm{P}(z, x) \rightarrow \mathrm{S}(z, y)) .
\end{aligned}
$$

It is easily verified that the two options are logically equivalent, the difference being merely heuristic. More generally, it can be shown that the five definitions of ' $b$ ' considered so far are all equivalent, provided only we assume $b$ to satisfy the basic properties of the standard boundary operator:

$$
\begin{array}{ll}
\text { (39) } & \mathrm{b}(x)=\mathrm{b}(\sim x) \\
\text { (40) } & \mathrm{b}(\mathrm{b}(x))=\mathrm{b}(x) \\
\text { (41) } & \mathrm{b}(x \times y)+\mathrm{b}(x+y)=\mathrm{b}(x)+\mathrm{b}(y)
\end{array}
$$

38 This strategy is followed in Smith (1993). 
which, in turn, are tantamount to (the mereologized version of) the standard Kuratowski axioms for topological closure: ${ }^{39}$

$$
\begin{aligned}
& \mathrm{P}(x, \mathrm{c}(x)) \\
& \mathrm{c}(\mathrm{c}(x))=\mathrm{c}(x) \\
& \mathrm{c}(x+y)=\mathrm{c}(x)+\mathrm{c}(y) .
\end{aligned}
$$

We have, then, various ways of introducing boundaries in the basic mereotopological framework at issue. If desired, we could also take either ' $b$ ' or ' $\mathrm{B}$ ' as a primitive and introduce ' $\mathrm{C}$ ' by definition, as per the following equivalences:

$$
\begin{aligned}
& \mathrm{C}(x, y) \leftrightarrow \mathrm{O}(x, y) \vee \mathrm{O}(x, \mathrm{~b}(y)) \vee \mathrm{O}(\mathrm{b}(x), y) \\
& \mathrm{C}(x, y) \leftrightarrow \exists z((\mathrm{P}(z, x) \wedge \mathrm{P}(z, y)) \vee(\mathrm{P}(z, x) \wedge \mathrm{B}(z, y)) \vee(\mathrm{B}(z, x) \\
& \wedge \mathrm{P}(z, y)))
\end{aligned}
$$

Regardless of how we do it, the outcome will be a theory free from the formal objections raised against its boundary-free cognates. This is easily verified. In fact, the resulting notion of a boundary is in many respects very close to the intuitive, common-sense notion that we are interested in. Boundaries are the surfaces of physical bodies, but also the beginnings or the endings of processes. A common feature of the former is that they are located in space but do not occupy space; a common feature of the latter is that they occur in time but do not take any time. In both cases, the feature is formally captured by the fact that boundaries do not have interior parts-a property which is in fact characteristic of boundaries. For convenience, let us integrate the boundary operator ' $b$ ' and the boundary relation ' $B$ ' with a boundary predicate 'Bd':

$$
\operatorname{Bd}(x)={ }_{\mathrm{df}} \exists y(\mathrm{~B}(x, y)),
$$

i.e., equivalently:

$$
\operatorname{Bd}(x)={ }_{\mathrm{df}} \exists y \exists z(y=\mathrm{b}(z) \wedge \mathrm{P}(x, y)) .
$$

Then we have:

39 See Kuratowski (1922). The equivalence with (39)-(41) stems from Zarycki (1927). 


$$
\operatorname{Bd}(x) \leftrightarrow \neg \exists z(\operatorname{IP}(z, x))
$$

Moreover, (39)-(41) suffice to guarantee that boundaries are closed under certain intuitive mereotopological properties-for instance:

$$
\begin{aligned}
& \mathrm{Bd}(x) \leftrightarrow x=\mathrm{b}(x) \\
& \mathrm{Bd}(x) \leftrightarrow \forall z(\mathrm{P}(z, x) \rightarrow \mathrm{B}(z, x)) \\
& \mathrm{B}(x, y) \wedge \mathrm{P}(z, x) \rightarrow \mathrm{B}(z, y) \\
& \mathrm{B}(x, y) \wedge \mathrm{B}(y, z) \rightarrow \mathrm{B}(x, z) \\
& \mathrm{B}(x, z) \wedge \mathrm{B}(y, z) \rightarrow \mathrm{B}(x+y, z) \\
& \mathrm{B}(x, z) \wedge \mathrm{O}(x, y) \rightarrow \mathrm{B}(x \times y, z) \\
& \mathrm{B}(x, z) \wedge \mathrm{P}(y, x) \rightarrow \mathrm{B}(x-y, z) \\
& \mathrm{P}(\mathrm{b}(x \times y), \mathrm{b}(x)+\mathrm{b}(y)) \\
& \mathrm{P}(\mathrm{b}(x+y), \mathrm{b}(x)+\mathrm{b}(y)) \\
& \mathrm{P}(\mathrm{b}(x-y), \mathrm{b}(x)+\mathrm{b}(y))
\end{aligned}
$$

The framework also allows us to capture some basic ontological intuitions that go beyond the repertoire of standard topology. For instance, consider the intuitive Aristotelian-Brentanian idea that boundaries are "parasitic" entities, i.e., can only exist as boundaries of something ${ }^{40}$ (contrary to the set-theoretic conception of boundaries as sets of ordinary, ontologically independent points). On the Whitehead-Clarke approach, this idea is of course captured by the very fact that boundaries are secondary entities- they don't live a life of their own; insofar as they are logically construed out of more fundamental entities, they depend on those entities. In the present context, where boundaries are on a par with the other objects of quantification, the relevant notion of dependence is more direct. It can be expressed as (60) or, more strictly, as (61):

$$
\begin{aligned}
& \operatorname{Bd}(x) \rightarrow \exists y(\operatorname{BP}(x, y) \wedge \neg \operatorname{Bd}(y)) \\
& \operatorname{Bd}(x) \wedge \mathrm{Cn}(x) \rightarrow \exists y(\operatorname{BP}(x, y) \wedge \mathrm{Cn}(y) \wedge \neg \operatorname{Bd}(y)) .
\end{aligned}
$$

If desired, we can also introduce dimensionality distinctions: boundaries can be zero-dimensional (a point), one-dimensional (a line), and two-

40 See, e.g., Aristotle's Metaphysics, 1060b12ff, and Brentano (1933, 1976), passim. Compare Chisholm (1984, 1994), Hestevold (1986), Bochman (1990), and especially Smith (1993), from which (60)-(61) are taken. 
dimensional (a surface); but no three-dimensional entity may count as a boundary.

$$
\begin{aligned}
& \text { (62) } \quad 0 \mathrm{D}(x)=_{\mathrm{df}} \quad \mathrm{Bd}(x) \wedge \forall y(\mathrm{P}(y, x) \rightarrow y=x) \\
& \text { (63) } 1 \mathrm{D}(x)==_{\mathrm{df}} \mathrm{Bd}(x) \wedge \neg 0 \mathrm{D}(x) \wedge \neg 2 \mathrm{D}(x) \wedge \exists y(2 \mathrm{D}(y) \wedge \mathrm{P}(x, y)) \\
& \text { (64) } 2 \mathrm{D}(x)=\mathrm{df} \quad \mathrm{Bd}(x) \wedge \forall y(\mathrm{P}(y, x) \wedge \mathrm{Cn}(y) \rightarrow \exists z \exists w(3 \mathrm{D}(z) \wedge 3 \mathrm{D}(w) \\
& \wedge y=\mathrm{c}(z) \times \mathrm{c}(w) \wedge \forall u(\mathrm{~B}(y, u) \rightarrow \mathrm{O}(u, z) \vee \mathrm{O}(u, w))) \\
& \text { (65) } 3 \mathrm{D}(x)=_{\mathrm{df}} \neg \mathrm{Bd}(x) \wedge \exists y(\mathrm{P}(y, x) \wedge x \neq y) \text {. }
\end{aligned}
$$

(The key definition here is (64), which exploits one arguably distinguishing peculiarity of two-dimensional boundaries_-viz., that any connected piece of such a boundary can never separate more than two discrete threedimensional bodies at a time. This is not quite free from counterexamples-e.g., when immaterial bodies such as holes or shadows are admitted-but we need not go into such details here.) We can then use these distinctions to do some justice to the intuition that boundaries typically have a fixed dimensionality, and in fact one dimension fewer than what they bound. ${ }^{41}$ Thus, let

$$
\begin{aligned}
& \mathrm{DI}(x, y)={ }_{\mathrm{df}} 0 \mathrm{D}(x) \vee(1 \mathrm{D}(x) \wedge \neg 0 \mathrm{D}(y)) \vee(2 \mathrm{D}(x) \wedge 2 \mathrm{D}(y)) \vee 3 \mathrm{D}(y) \\
& \mathrm{DPI}(x, y)={ }_{\mathrm{df}} \mathrm{DI}(x, y) \wedge \neg \mathrm{DI}(y, x)
\end{aligned}
$$

(dimensional inclusion and proper inclusion, respectively). Then we may strengthen (61) to:

$$
\operatorname{Bd}(x) \wedge \mathrm{Cn}(x) \rightarrow \exists y(\mathrm{BP}(x, y) \wedge \mathrm{Cn}(y) \wedge \mathrm{DPI}(x, y)) .
$$

All of this should shed some light on the effects of admitting boundaries in the basic mereotopological framework, and I think there is some evidence that the overall outcome enjoys several nice features. The fact remains, however, that this way of proceeding requires a full endorsement of the opposition between open and closed entities. This is implicit in the foregoing, and is in fact an ineluctable feature of the approach. So, the question must now be faced: Is there any way of paying this tribute without running

41 This thesis is also Brentanian. It plays a significant role, for instance, in Jackendoff's (1991) analysis of path and event structures. 
into the sorts of problem mentioned earlier in connection with that opposition?

\section{More on the Open/Closed Opposition}

I wish to argue that the answer need not be in the negative. The open/closed distinction is not immediately obvious. But whatever drawbacks it may have, the troubles are not the ones expressed in the above quote from Cohn and his associates (which in turn reflect the traditional Brentanian misgivings about Bolzanian theories).

In fact, I believe that in this regard the open/closed distinction is not as "monstruous" as it might seem-on the contrary. For instance, a most natural characterization of the standard three-fold classification of event types can be given precisely by treating processes (such as Susan's swimming) as non-closed events, accomplishments (Susan's crossing of the Channel) as closed processes, and achievements (Susan's reaching of the French coast) as parts of the corresponding boundaries. ${ }^{42}$ Also in the spatial realm, it is not impossible to think of entities which do not include their own boundaries. Holes, for instance, are bounded from the outside: the boundary of a hole is the surface of its host.

Secondly, and perhaps more importantly, the main worry about the open/closed distinction - that "once we allow bodies to break up into parts, . . . one part will map to a closed region, and the other to a semi-open region"- is grounded on a model of breaking (cutting, dissecting, etc.) that is questionable. Topologically, the cutting of an object in half is no bloodstained process - there is no question of which of the two severed halves keeps the boundary, leaving the other open and bleeding (as it were). Rather, the topological model is that of an oil drop which is dissected so as to produce two separate drops. There is one surface, and this surface eventually splits into two. (Think also of a soap bubble splitting.) There is some

42 I have done so in joint work with Fabio Pianesi. See Pianesi and Varzi (1994). Compare Desclés (1989) and Jackendoff (1991). The "standard" classification is of course due to Vendler (1957). 
magic in this process, admittedly. But this is true of every topological catastrophe, as when you drill a hole through an object. The instantaneous event of a sphere's turning into a torus is just as magical. ${ }^{43}$ Thus, if we confine ourselves to extensional mereotopology, the seeming difficulty involved in the dissection of an object is not an idiosyncrasy of a boundary-based theory, but a sign of a more general phenomenon whose complete assessment will likely require at least a step into the territory of naive kinematics. ${ }^{44}$ (Accordingly, I take it that the intuitive feeling that dissecting solids "reveals matter in their interiors" and "brings to light new surfaces," to use Ernest Adams' words, ${ }^{45}$ is ill-grounded. Even if we imagine cutting through a bar of white soap whose top surface is painted red, the white superficial parts appearing along the cut are not "brought to light" from the interior. Simply, the surface of the soap undergoes a topological deformation of the sort described above, yielding a concomitant laceration in the color coat which must in turn be explained along the same lines-though the relevant boundary is now one dimension fewer.)

I don't know exactly how this intuitive explanation can be extended to account also for other forms of dissection-breakage, for instance. Some cases would seem rather clear. A fracture originates somewhere on the surface and rapidly spreads through the object until two parts are-mirabile dictu - separated. The fracture does not reveal the interior; rather, it comes from a continuous deformation of the one surface. (Think of a slow motion movie featuring the pulling of a party popper.) Other cases might not admit of such a simple model. (Imagine pulling on opposite ends of a perfectly rigid brick of homogeneous matter.) For my purposes, however, a complete picture is not necessary. All I wish to emphasize is that the classical Brentanian misgivings are based on the assumption that dissection will always leave a pair of open/closed parts, and this assumption may be reasonably challenged in those cases where it would seem to yield unreasonable results.

43 Compare Casati and Varzi (1994), ch. 6: "The natural history of discontinuities".

44 E.g., along the lines of Davis (1993).

45 Adams (1984), p. 400. In the same spirit, Zimmerman (1996b) speaks of "a part of the object which was first imbedded in the [object] and then disclosed wearing a new skin" (p. 25). 
Other cases are less clear, but so are our intuitions. There is a complicated kinematic story to tell.

The above line of reasoning seems to apply also in relation to other forms of misgiving. For instance, Dean Zimmerman has a nice argument to the effect that the open/closed distinction yields an implausible world in which

\begin{abstract}
a certain class of objects [the closed ones] are unaccountably deferential to one another-always just managing to step out of one another's way-while they bang heedlessly into the members of another class of objects [the open ones]. Surely repulsive forces would have to be posited to explain such behavior. [...] But why should a certain shape of extended object be necessarily such that objects of that shape possess special repulsive powers? ${ }^{46}$
\end{abstract}

The idea here is that we may imagine the same experiment performed twice. First we take an open cube and push it toward a closed cube with sufficient force so that they come into contact in two seconds. Then we do the same with two closed cubes. What reason can we offer to explain why in this case the two cubes are not coming into contact after two seconds? Was their progression slower, or did it end sooner? I concede that these are embarrassing questions, for "we seem forced to attribute repulsive powers of some kind to the cubes-an ability each cube has to 'let the other know' that it has a skin of simples so that, if both the approaching surfaces are closed, the bodies can make sure to slow down or stop." But to me there seem to be other possibilities. Perhaps the two closed cubes will indeed come into contact. From the fact that two closed entities cannot be in contact it does not follow that they cannot come into contact, just as from the fact that two parts are connected it does not follow that they cannot be separated. Only, the coming into contact (just as the separation) determines a true topological catastrophe: there is a breaking through the relevant boundary parts and the two objects become one. (Think also of the two soap bubbles fusing into each other.) The two processes are dual: fusing is the reverse of splitting. And both involve a seemingly magical moment which runs afoul of the confines of extensional mereotopology and calls for a full kinematic account.

46 Zimmerman (1996b), p. 12; the quote below is from the same page. Compare Kline and Matheson (1987), pp. 513-14, for a related argument. 
As I said, these considerations do not make an argument for the open/ closed opposition. But I take them to go at least some way in the direction of dispelling the clouds of Brentanian suspicion that surround it. We still have Peirce's puzzle, however. And here the opposition seems truly problematic. For in this case, the puzzle $i$ s purely extensional. Take any entity $x$. Does the boundary (or any piece thereof) belong to $x$ or to $\sim x$ ? Does it inherit the properties of the object or those of the complement? How can we answer these questions without contravening the principle of sufficient reason?

Again, some cases are simpler than others. For instance, we may find good reasons to maintain that material bodies such as stones or soap bars are the owners of their boundaries - their surfaces, in fact. Thus, where the complement meets an object of this sort, it will be open. (The object, in turn, will be the closed complement of the complement.) We may also, as we just saw, argue that immaterial bodies such as holes are not the owners of their boundaries: these belong to the material bodies that host the holes. Thus, where the two meet, the complement (host) is closed and the entity (hole) open. (The hole, in turn, is part of the host's open complement.) But even such simple cases immediately give rise to some dilemmas. For consider a typical hole that goes through a sphere-a perforation. It is in contact with the sphere; but there are also some regions of its boundary-corresponding to the entrance and the exit of the hole-that are not so in contact. (Pat Hayes calls them "portals". ${ }^{47}$ ) They are free. Or, if you prefer, they are in contact with the immaterial, airy body which constitutes the complement of the sum of the hole plus the sphere. The question is: Where do we place the boundary corresponding to those regions? With the hole? With the complement? Both answers seem bizarre. And either choice would be thoroughly arbitrary.

I think we may respond that such dilemmas are real, and yet insist on keeping the theory as it is. For, we may argue, the actual ownership of a boundary is not an issue that the theory must be able to settle. The theory only needs to explain what it means for two things to be connected. It doesn't need to give a full explanation of the underlying metaphysical grounds. After all, whether the boundary between hole and complement be-

47 Hayes (1985), p. 79ff. 
longs to the hole or to the complement is a question to be answered by a theory of holes, not by a general theory of boundaries.

By the same token, we can say that every instance of Peirce's puzzle (and of its temporal analogues) is truly problematic and yet extrinsic to our present concerns. Give me a theory of black spots, and make sure to tell me who gets the boundary - the spot or the background. Give me a theory of events, and make sure to tell me which gets the boundary-the movement or the rest. If we accept this response, we have a way of disposing of the puzzle in its general form, and the last of the difficulties usually attributed to the open/closed opposition is also overcome.

\section{Bona Fide versus Fiat Boundaries}

There is, to be sure, a derivative problem to be noted here, one that may yet prove decisive against the open/closed opposition. For consider again the cutting of the soap bar. I argued that the cutting does not bring to light a new surface. But, of course, we can conceptualize a new, potential surface right there where the cut would be. In fact, we can conceptualize as many potential boundaries as we like-two, one, even zero-dimensional boundaries. As Barry Smith has recently pointed out, ${ }^{48}$ our ordinary description of the world very often and quite naturally makes reference to "fiat" boundaries of this sort, even in the absence of any corresponding spatiotemporal discontinuity or qualitative heterogeneity among the parts. My waist, the Equator, the North Pole, Susan's turning 20 years old, the beginning of the seventh minute of play during a soccer game-you can draw boundaries where and when you like, as often as you like. Again: the border between France and Italy, the kitchen's doorsill, the center of mass of Toronto's dome stadium. These are not full-fledged boundaries of the sort discussed so far, in that they do not demarcate what they bound through any "intrinsically privileged feature of the underlying reality." ${ }^{49}$ But it is clear that any theory of boundaries must be capable of accounting for them as well.

\footnotetext{
48 See Smith (1994, 1995b).

49 The quote is from an extended, unpublished version of Smith (1994).
} 
Now, here the open/closed distinction seems to face a real problem. On the theory under examination, all boundaries are perfectly symmetrical, and contact is only possible through a boundary belonging to one but not the other of two adjacent entities. This may be true of real, "bona fide" boundaries-if the foregoing arguments are accepted-even though in some cases it may be impossible to establish which entity the boundary belongs to. However, in the case of fiat boundaries this epistemological way out does not seem to apply. In the case of fiat boundaries, there is no fact of the matter that can support their belonging to one or the other of two adjacent entities. The boundary demarcating the right and left hemispheres of a sphere of homogeneous stuff is not only hard to assign to either half. It cannot be assigned, no matter what our theory of spheres looks like. The boundary between France and Italy does not belong to France, and it does not belong to Italy either. It may belong to both, if one will (and I'll come back to this shortly), but it surely does not belong to one and not the other. And surely enough, we can't just say that it belongs to neither, treating both France and Italy as semi-open entities. The right and left hemispheres use up the whole sphere by definition - no boundary can be left out.

To this problem I react as follows. Yes, boundaries of this sort are at odds with the theory. But not because they revive the old problems. Fiat boundaries are potential in that they are not actually separating anything from anything - they don't mark any actual discontinuity. However, this is not to say that fiat boundaries can be actualized. That would be again the same mistake we saw in connection with the modelling of such operations as cutting, slicing, and the like. There is no way you can bring to light the Equator by actually cutting the Earth in half. Dissecting the Earth would give you two half Earths, each enveloped by a closed connected surface. (Think again of the soap bubble splitting in two.) This is not a way of bringing the Equator to life. Indeed, once the process is completed, the Equator is dead forever. And there (or about there) where we had the Equator we now have two perfectly congruent faces, one on each half. To put it differently, fiat boundaries are not the boundaries that would envelop the interior parts to which they are associated in case those parts were brought to light by removing the rest (unless removal is here understood as instantaneous annihilation-I wouldn't know how to deal with that). Wherever you have a fiat 
boundary, you can have bona fide boundaries. But the former never turns into the latter-at most, it leaves room for them. ${ }^{50}$

Thus, the modal model underlying the above objection to the open/ closed opposition is ill-grounded. When we conceptualize a fiat boundary $x$, we are in a sense moving to a possible world where $x$ actually involves some interior spatial or temporal discontinuity, and where the trouble of its belongingness arises. But this is a somewhat hasty and misleading picture. A better picture would have to exploit a counterpart-theoretic account: When we conceptualize $x$, we move to a possible world where $x$ is replaced by two counterparts, $x_{1}$ and $x_{2}$, one belonging to the boundary of one side, and the other belonging to the boundary of the second side. The actual transition from one world to the other is a complicated kinematic story. But the topology is rather clear. (This goes well with the spatial case. In the temporal realm, with temporal fiat boundaries such as Susan's turning 20 years old, the story is less clear insofar as we cannot rely on a corresponding notion of cutting. But again, the answer does not change: fiat boundaries are not genuine boundaries, not even potentially. They are place-holders for possible genuine boundaries.)

\section{Coincidence of Boundaries}

With all this, we save the open/closed account for bona fide boundaries, but we still need to provide an account of fiat boundaries as such. For even if we deny them a genuine boundary status, we need not be Platonists to agree with Frege that such things are real:

One calls the equator an imaginary line, but it would be wrong to call it a line that has merely been thought up. It was not created by thought as the result of a psychological process, but is only apprehended or grasped by thought. If its being apprehended were a matter of its coming into being, then we could not say anything positive about the equator for any time prior to this supposed coming into being. 51

50 Zimmerman (1996a) made me realize that this view seems to have an ancestor in Suarez; see for instance Disputationes, $\S 56$. A more detailed examination can be found in Zimmerman (1996b).

51 Frege (1884), p. 35. 
In other words, I have said that fiat boundaries are not actual boundaries (and do not even qualify as potential, since they never turn into genuine boundaries). But, in a sense, they are actual nonetheless: they are actual fiat boundaries. And it would be good to know what goes on when two (potential) parts of an actual entity are separated by such a thing: which part does the fiat boundary belong to?

Smith's own explanation is that in this case the right thing to say would be that the two parts actually share the fiat boundary. The boundary belongs to both. Or, more precisely, each part has its own fiat boundary, and the two boundaries coincide. This draws on Brentano's view, which in fact regards the possibility of coincidence as a distinguishing feature of all boundaries: boundaries are located in space-time but do not occupy space-time, and can therefore be perfectly co-located with one another. Thus, for instance, on Brentano's account Peirce's puzzle is immediately solved by allowing a line to be of two distinct colors, that is, more precisely, by allowing two differently colored lines to coincide: "If a red surface and a blue surface are in contact with each other, then a red and a blue line coincide." 52 And when an object is cut in half, neither of the two newly exposed parts comes out open, for each already has a complete boundary (partially coinciding with that of the other) before the cut. Likewise, in the temporal realm, the boundary (end) of a thing's being in motion and the boundary (beginning) of the thing's being at rest will coincide.

I don't mean to go into the details of Brentano's theory. A detailed formulation has been put forward by Roderick Chisholm in a number of papers, and recently revised by Smith himself. ${ }^{53}$ Just to illustrate, one may take coincidence as a primitive relation-say ' $\mathrm{W}(x, y)$ ', for " $x$ wholly coincides with $y$ "- and then define boundaries as those entities that can enter this relation. (Or one could define coincidence in terms of the relation of

52 Brentano (1976), p. 41. See also (1924), pp. 357f. The opposition between location and occupation is not strictly speaking Brentanian, and applies to other entities as well (e.g., holes and events). See Casati and Varzi (1996).

53 See Chisholm $(1984,1992 / 93)$ and Smith $(1995 a, 1997)$. In the artificial intelligence literature, one author who has a rather similar theory is Patrick Hayes: see his (1985), §5. 
spatiotemporal co-location, a relation whose basic axiomatic structure is rather clear. ${ }^{54}$ ) Thus, $\mathrm{W}$ must be symmetric and transitive:

$$
\begin{aligned}
& \mathrm{W}(x, y) \rightarrow \mathrm{W}(y, x) \\
& \mathrm{W}(x, y) \wedge \mathrm{W}(y, z) \rightarrow \mathrm{W}(x, z),
\end{aligned}
$$

hence conditionally reflexive:

$$
\mathrm{W}(x, y) \rightarrow \mathrm{W}(x, x),
$$

to which one may add mixed mereological postulates to guarantee at least weak monotonicity and closure under general fusion:

$$
\begin{aligned}
& \mathrm{P}(x, y) \wedge \mathrm{W}(y, z) \rightarrow \exists w(\mathrm{P}(w, z) \wedge \mathrm{W}(x, w)) \\
& \exists w(\phi w) \wedge \forall y(\phi y \rightarrow \mathrm{W}(x, y)) \rightarrow \mathrm{W}(x, \sigma y(\phi y)) .
\end{aligned}
$$

(This means that something may coincide with some of its proper parts: for instance, the sum of two coincident lines coincides with each line. Thus, coincidence falls short of identity.)

Now, we don't need to buy this as a general theory of boundaries. For one thing, we seem to need an independent characterization of boundaries anyway, for it is plausible to speak of coincidence with respect to other kinds of entities: the statue and the bronze it is made of, for instance; or the rotation and the getting warm of a metal ball that is simultaneously rotating and getting warm, to take a case where the terms of the coincidence relation are categorially homogeneous. ${ }^{55}$ More specifically, I don't think this is a good general theory if connection and related notions are to be explained using coincidence of boundary parts. For, on the one hand, it is not clear how the theory could handle entities which do not include their own boundaries, i.e., entities that are bounded "from the outside" (like holes and suchlike things, or like processes). The only options would be either to banish such entities altogether, or to insist that they are all closed, that they all own

54 This is investigated in Casati and Varzi (1996).

55 This was Davidson's (1969) counterexample to the spatiotemporal criterion for event identity. Defenders of the criterion will presumably be undisturbed by my misgivings here. 
their own boundaries - and both options would be stipulative. ${ }^{56}$ On the other hand, if such entities were admitted, there would be no way we can ensure that (some) boundaries be symmetrical. On this account, a boundary would always bound only its associated entity, not the complement (which may as well be unbounded unless we stipulate to the contrary), and I don't see any reasonable way of avoiding that. But then the fundamental distinction between interior and tangential parts becomes fuzzy. Since lack of external connections may be due simply to a lack of suitable boundaries in the complement, it may well happen that an object's tangential parts be classified as parts of the object's interior. This is unacceptable. And it makes it impossible to rely on interior parts to distinguish between weak and strong connection (contiguity and continuity), which I earlier set forth as a major desideratum for any common-sense theory of spatiotemporal entities.

Even so, we can still exploit the idea that coincidence is a distinguishing property of certain boundaries. In particular, we may follow Smith and accept this as an exclusive boundary theory for the fiat world: fiat boundaries are those boundaries that can enter the coincidence relation:

$$
\begin{aligned}
& \mathrm{FBd}(x)={ }_{\mathrm{df}} \operatorname{Bd}(x) \wedge \mathrm{W}(x, x) \\
& \mathrm{FB}(x, y)=_{\mathrm{df}} \operatorname{FBd}(x) \wedge \operatorname{BP}(x, y) .
\end{aligned}
$$

Then the above becomes a theory of what goes on when two (potential) parts of an actual entity are separated by fiat: they are $\mathrm{W}$-connected, i.e., their fiat boundaries coincide:

$$
\mathrm{WC}(x, y)=_{\mathrm{df}} \neg \mathrm{O}(x, y) \wedge \exists z \exists w(\mathrm{FB}(z, x) \wedge \mathrm{FB}(w, y) \wedge \mathrm{W}(z, w)) .
$$

We can still speak of the Equator as of a single thing. But, strictly speaking, such a thing is to be recognized as being made up of two things, two per-

56 Cartwright (1975) has argued that all bodies (more precisely, all receptacles of material bodies) are open, their surface always being between them and their complement. (This reflects Descartes' notion of "superficies": see Principles of Philosophy, Part 2, Principle 15.) Of course this option-all closed vs. all open-is "hardly worth of serious dispute", as Cartwright says (p. 154). My point here is that the option should rather include the possibility of some things being closed and some open. 
fectly coinciding fiat boundaries bounding the Northern and the Southern hemisphere, respectively.

Does this leave us with the consequence that two entities may either be (ideally) separated by fiat boundaries or share a bona fide boundary without there being a detectable difference? Someone might regard that as an unacceptable or at least highly indesirable consequence. ${ }^{57}$ Really I should think this would not be a serious drawback from our present perspective, insofar as it pertains to the epistemology rather than to the ontology of boundaries. But there is no need to go into that distinction in order to dispose of the objection, for there is no room for undetectable differences here. Whenever a closed and an open entity are joined together, the result is a continuous object in which the relevant boundary part (that part of the boundary of the closed object which came into contact with the open part of the other object) disappears in the interior. That boundary part does not bound anything anymore-it is no longer a boundary part. We can say where it was, as it were. But if we do so, we do so with the help of fiat boundaries. And surely enough these won't introduce any detectable differences.

\section{Concluding Remarks}

To sum up: (i) I have argued that boundaries, continuity, and the possibility of contact are all essential features of our conceptual scheme and occupy a prime place in the prima facie ontology inherent in common sense; (ii) I have argued that boundaries may be a questionable ingredient, but I have also found no satisfaction in customary attempts to explain them away as mere façons de parler; (iii) I have reckoned that accepting boundaries will call for an account of the apparently troublesome distinction between open and closed entities, but I have also found the distinction to be ultimately unproblematic (and to some extent even desirable); (iv) finally, I have submitted that a theory of genuine boundaries-based on the open/closed opposi-

57 Zimmerman (1996b), § 5, argues that a Bolzanian metaphysics is untenable on account of its introduction of undetectable differences between open entities and their closures (among other reasons). Gotts et al. (1996), § 4, have similar misgivings. 
tion-must be supplemented by a suitable theory of fiat boundaries, based for instance on the coincidence relation. There is still one loose end at this point: What is the exact relationship between two adjacent closed entities? They are not connected, if this is understood in terms of the $C$ relation: no two closed entities are ever connected in that sense, not even externally connected (EC). But we do want to say that they are in touch, somehow-that nothing can be squeezed in between them.

Roughly, I see two options here. The first is simply to defer the issue to some different chapter of an overall theory of common-sense space and time. For instance, one could regard this as a metric issue, defining two closed entities to be in touch (in this sense) if the distance between them is arbitrarily small. The second option is that we do something similar without leaving the confines of mereotopology. Consider, for instance, the following relation: ${ }^{58}$

$$
\mathrm{T}(x, y)=_{\mathrm{df}} \forall z(\mathrm{P}(x, z) \wedge \mathrm{Op}(z) \rightarrow \mathrm{O}(\mathrm{c}(z), y)) .
$$

This would capture the intuition that nothing can lie between two touching entities. (It would also, I suppose, capture the Whiteheadian intuition that two things are in contact if there is a suitable abstractive set of nested regions each of which overlaps both things.) However, as a general characterization (77) is obviously incompatible with the conception of space as continuous: if spatial regions are included in the domain, $T$ collapses onto $C$ unless we are ready to adopt a somewhat non-standard Wolffian model of discrete space. What we would really want to say is that (77) holds relative to the domain of objects (as opposed to spatiotemporal regions), so we would need a theory of objects at least, or a suitable sortal logic to keep track of the relevant distinctions. Moreover, since the intuitive rationale behind this characterization is that nothing can circumclude one object without overlapping the other, we would need to rely on a suitable modal logic. This may be quite costly, since classical extensional mereology does not fare well with modalities; yet I am inclined to believe that an account along these lines would be germane to the notion of touching involved in common sense, and would also capture an

58 This is a slightly amended version of a notion of weak contact studied in Vieu (1991), esp. pp. 250-54. 
important sense in which ordinary reasoning about boundaries involves an abstractive process. (One might also view the modal dimension as reflecting a strictly procedural feature of the common-sense notion of contact. This would be in the spirit of Adams' operationalist approach, which in turn is inspired by Euclid's account of parallelism. In the latter case, the relation is defined operationally to hold between two lines $a$ and $b$ just in case they do not meet if they are "produced indefinitely in both directions." In the case of touching, we look for suitable operational tests-specifically, the production of separate "boundary covers"- to determine empirically whether two given bodies are actually separate. The full characterization of these tests is itself rather involved, and I refer to Adams' own works for the details. ${ }^{59}$ )

With all this, the account is certainly incomplete and not completely certain. We have a sketch of a boundary-based theory of spatiotemporal connection, but the full story would have to include a treatment of several aspects that I hardly broached here. I should like to conclude by mentioning at least three of them.

(a) Granularity. For most representations, boundaries need not have zero thickness: crusts, skins, barks, and the like, as well as much thicker layers of stuff or spatial zones such as the Earth's surface or the no man's land that used to surround West Berlin, may all be viewed as boundaries, on a suitable degree of granularity. As Jackendoff puts it:

A stripe that bounds a circle . . is locally 2 -dimensional, not 1-dimensional. What makes the stripe a boundary for the circle is its schematization as a line (its primary dimension) elaborated by a cross-section (its secondary dimension). ${ }^{60}$

We may think here of introducing a pseudo-boundary operator along the following lines: ${ }^{61}$

$$
\mathrm{b}^{\star}(x)={ }_{\mathrm{df}} \sigma z(\operatorname{TP}(z, x) \wedge \forall y(\mathrm{P}(y, z) \rightarrow y=z)) .
$$

That is, a pseudo-boundary is the outmost layer of mereotopological atoms. This is in contrast with the principle that boundaries have one dimension fewer than what they bound (see (68)), but from a cognitive perspective this

\footnotetext{
59 See especially Adams (1973), §§ iv-ix; (1986), § 2; (1996), § 6.

60 Jackendoff (1991), p. 32 (my emphasis).

61 This is, slightly amended, the "skin" operator of Randell et al. (1992b), p. 173.
} 
notion may well be worth studying. (Note the difference from the notion of boundaries as the "topmost layer of atoms" studied by certain branches of contemporary physics—what Stroll calls the "Somorjai Conception" of surfaces. ${ }^{62}$ The latter have divisible physical bulk; pseudo-boundaries do not, insofar as the internal structure of their constituent atoms is mereotopologically irrelevant.)

(b) Vagueness. The objects and events of ordinary experience do not always have sharp boundaries. Clouds, mountains, towns, let alone the figures of an impressionist painting, seem to elude the idealized notion of bounded object presupposed by a topologically oriented account. Likewise, we may well agree that the press conference will start at $4 \mathrm{pm}$ on the dot; but the exact temporal boundary of the election campaign (let alone its spatial boundary) is sure to be fuzzy. This may be understood in a strict sense, as for instance Michael Tye has urged:

There is no line which sharply divides the matter composing [Mount] Everest from the matter outside it. Everest's boundaries are fuzzy. Some molecules are inside Everest and some molecules outside. But some have an indefinite status: there is no objective, determinate fact of the matter about whether they are inside or outside. ${ }^{63}$

If this is correct, then one should presumably think of the basic mereotopological relations (' $P$ ', ' $C$ ', or both) as vague relations, and the account given here calls for some rethinking. On the other hand, one may also-and I am inclined to-understand the haziness of ordinary boundaries to be a merely semantic fact. In Quine's words:

Countless minutely divergent aggregates of molecules have equal claim to being my desk. True enough; but this circumstance attests only to the vagueness of the term 'desk,' or 'my desk,' and not to that of 'physical object.' Each of these visually indiscriminable candidates for the status of being my desk is a distinct physical object, individuated by the requirement of spatiotemporal coextensiveness. 64

If this is correct, then there is no specific issue for mereotopology, though the overall account will have the somewhat unfortunate feature of resting on

\footnotetext{
62 See Stroll $(1979,1988)$.

63 Tye (1990), p. 535.

64 Quine (1985), pp. 167-68.
} 
unsettled questions in the theory of reference. ${ }^{65}$ (There is also the epistemic option: the things are sharp, the names are also sharp, and we simply have troubles figuring out exactly what things are picked out by what names. That raises further questions, though. For what makes a name a name of what, if not the way we use it?) Be that as it may, vagueness is definitely a pervasive phenomenon if our concern is the description of the ordinary world, and a satisfactory theory of boundaries should eventually include some way of dealing with it. ${ }^{66}$

(c) Dependence. One reason for employing a topological representation based on mereology rather than set theory is that the latter does not allow us to do justice to the intuition that boundaries are ontologically dependent on the entities they bound. You cannot remove the surface from the table, just as you can't remove a hole from its piece of Swiss cheese. This is not merely a question of conceptual dependence. (There is no wife without a husband; but it is not true of any wife that she-that person-could not exist alone.) The dependence of boundaries on their hosts is much stronger. That surface can only exist as a surface of a table-perhaps only as a surface of that table. In a mereotopological setting, this form of dependence is partly captured by principles such as (60)-(61), and by whatever version of (68) (the dimensionality principle) we endorse. However that is only the beginning, and a fuller account is in order for the theory to have adequate explanatory strength. ${ }^{67}$

These are only some of the issues that still need be taken into account. They are by no means easy to deal with. But I should think their study will further enhance the centrality of boundaries in our conceptual scheme, as well as their intimate ontological and epistemological make-up. ${ }^{68}$

65 This seems to me to be the moral of the long debate that followed Evans' (1978) provocative argument. See Sainsbury (1995) and Copeland (1995) for a recent exchange.

66 Some work in this direction (naturally focusing on the representation of vague regions, as opposed to vague boundaries) has been done by authors in the boundary-free tradition of Whitehead and Clarke; see e.g. Cohn and Gotts (1996).

67 On the intricacies of ontological dependence see, e.g., Simons (1987), ch. 7. Fine (1995) explores an account in terms of explicit first-order axiomatizations of the dependence relation.

68 This is a revised and extended version of a paper presented at the 5th International 


\section{References}

Adams, E. W. (1973) “The Naive Conception of the Topology of a Surface of a Body," in P. Suppes (ed.), Space, Time and Geometry, Dordrecht: Reidel, pp. 402-24.

— (1984) "On the Superficial," Pacific Philosophical Quarterly 65, 386-407.

- (1986) "On the Dimensionality of Surface, Solids, and Spaces," Erkenntnis 24, 137-201.

- (1996) "Topology, Empiricism, and Operationalism," The Monist 79, 1-20.

Allen, J. F. (1981) “An Interval-Based Representation of Temporal Knowledge,” Proceedings of the 7th International Joint Conference on Artificial Intelligence, Vancouver: Morgan Kaufmann, Vol. 1, pp. 221-26.

- (1984) "Towards a General Theory of Action and Time," Artificial Intelligence 23, 123-54.

Asher, N., and Vieu, L. (1995) “Toward a Geometry of Common Sense: A Semantics and a Complete Axiomatization of Mereotopology," in Proceedings of the 14th International Joint Conference on Artificial Intelligence, San Mateo, CA: Morgan Kaufmann, pp. 846-52.

Aurnague, M., and Vieu, L. (1993) "A Three-Level Approach to the Semantics of Space," in C. Z. Wibbelt (ed.), The Semantics of Prepositions: From Mental Processing to Natural Language Processing, Berlin: Mouton de Gruyter, pp. 393-439.

Biacino, L., and Gerla, G. (1991) "Connection Structures,” Notre Dame Journal of Formal Logic 32, 242-47.

Bochman, A. (1990) "Mereology as a Theory of Part-Whole," Logique et Analyse 129/30, 75-101.

Bolzano, B. (1851) Paradoxien des Unendlichen, hrsg. von F. Př ihonský , Leipzig: Reclam (Eng. trans. by D. A. Steele, Paradoxes of the Infinite, London: Routledge \& Kegan Paul, 1950).

Brentano, F. (1924) Psychologie vom empirischen Standpunkt, 2. Aufgabe, hrsg. von O. Kraus, Leipzig: Meiner (Eng. trans. ed. by L. L. McAlister, Psychology from an Empirical Standpoint, London: Routledge \& Kegan Paul, 1950).

- (1933) Kategorienlehre, hrsg. von A. Kastil, Hamburg: Meiner (Eng. trans. by R. M. Chisholm and N. Guterman, The Theory of Categories, The Hague/Boston/London: Nijhoff, 1981).

- (1976) Philosophische Untersuchungen zu Raum, Zeit und Kontinuum, hrsg. von S. Körner and R. M. Chisholm, Hamburg: Meiner (Eng. trans. by B. Smith, Philosophical Investigations on Space, Time and the Continuum, London: Croom Helm, 1988).

Workshop Time, Space and Movement: Meaning and Knowledge in the Sensible World, Château de Bonas, Gascogne (France), June 1995. I am very thankful to the organizers and to the audience for stimulating comments and discussion. I also owe much to exchanges I have enjoyed with Roberto Casati, Tony Cohn, Antony Galton, Fabio Pianesi, Barry Smith, Roy Sorensen, Laure Vieu, and Dean Zimmerman. 
Broad, C. D. (1923) Scientific Thought, New York: Harcourt.

Cartwright R. (1975) "Scattered Objects," in K. Lehrer (ed.), Analysis and Metaphysics, Dordrecht: Reidel, pp. 153-71.

Casati, R., and Varzi, A. C. (1994) Holes and Other Superficialities, Cambridge, MA, and London: MIT Press.

- (1995) "Basic Issues in Spatial Representation,” in M. De Glas and Z. Pawlak (eds.), Proceedings of the 2nd World Conference on the Fundamentals of Artificial Intelligence, Paris: Angkor, pp. 63-72.

- (1996) “The Structure of Spatial Localization," Philosophical Studies 82, 205-39.

- (1997) "Spatial Entities," in O. Stock (ed.), Spatial and Temporal Reasoning, Dordrecht/Boston/London: Kluwer, pp. 73-96.

Chisholm, R. M. (1984) "Boundaries as Dependent Particulars," Grazer philosophische Studien 10, 87-95.

- (1992/93) "Spatial Continuity and the Theory of Part and Whole. A Brentano Study," Brentano Studien 4, 11-23.

- (1994) "Ontologically Dependent Entities," Philosophy and Phenomenological Research 54, 499-507.

Clarke, B. L. (1981) “A Calculus of Individuals Based on 'Connection'," Notre Dame Journal of Formal Logic 22, 204-18.

- (1985) "Individuals and Points," Notre Dame Journal of Formal Logic 26, 61-75.

Cohn, A. G., and Gotts, N. M. (1996) “The 'Egg-Yolk' Representation of Regions with Indeterminate Boundaries," in P. Burrough and A. U. Frank (eds.), Geographic Objects with Indeterminate Boundaries, London: Taylor and Francis, pp. 171-87.

Copeland, B. J. (1995) “On Vague Objects, Fuzzy Logic and Fractal Boundaries," Southern Journal of Philosophy 33 (Supplement), 83-96.

Davidson, D. (1969) "The Individuation of Events," in N. Rescher (ed.), Essays in Honor of Carl G. Hempel, Dordrecht: Reidel, pp. 216-34.

Davis, E. (1993) "The Kinematics of Cutting Solid Objects," Annals of Mathematics and Artificial Intelligence 9, 253-305.

Desclés, J.-P. (1989) "State, Event, Process, and Topology," General Linguistics 29, 159-200.

de Laguna, T. (1922) “Point, Line, and Surface, as Sets of Solids," Journal of Philosophy 19, 449-61.

Eschenbach, C., and Heydrich, W. (1995) "Classical Mereology and Restricted Domains," International Journal of Human-Computer Studies 43, 723-40.

Evans, G. (1978) “Can There Be Vague Objects?,” Analysis 38, 208.

Fine, K. (1995) "Part-Whole," in B. Smith and D. W. Smith (eds.), The Cambridge Companion to Husserl, New York: Cambridge University Press, pp. 463-85.

Forrest P. (1996) "From Ontology to Topology in the Theory of Regions," The Monist 79, 34-50.

Frege, G. (1884) Die Grundlagen der Arithmetik. Eine logisch-mathematische Untersuchung über den Begriff der Zahl, Breslau: Köbner (Eng. trans. by J. L. Austin, Foundations of Arithmetic, Oxford: Basil Blackwell, 1950). 
Galton, A. (1994) "Instantaneous Events," in H. J. Ohlbach (ed.), Temporal Logic: Proceedings of the ICTL Workshop, Saarbrücken: Max-Planck-Institut für Informatik, Technical Report MPI-I-94-230, pp. 4-11.

Gerla G. (1995) "Pointless Geometries," in F. Buekenhout (ed.), Handbook of Incidence Geometry, Amsterdam: Elsevier, pp. 1015-31.

Gibson, J. J. (1966) The Senses Considered as Perceptual Systems, London: Allen and Unwin.

- (1979) The Ecological Approach to Visual Perception, Boston: Houghton Mifflin.

Goodman, N. (1956) "A World of Individuals," in J. M. Bochenski, A. Church, and N. Goodman, The Problem of Universals. A Symposium, Notre Dame: University of Notre Dame Press, pp. 13-31.

Gotts, N. M. (1994) "How Far Can We 'C'? Defining a 'Doughnut' Using Connection Alone," in J. Doyle, E. Sandewall, and P. Torasso (eds.), Principles of Knowledge Representation and Reasoning: Proceedings of the Fourth International Conference, San Mateo, CA: Morgan Kaufmann, pp. 246-57.

Gotts, N. M., Gooday, J. M., and Cohn, A. G. (1996) “A Connection Based Approach to Common-Sense Topological Description and Reasoning," The Monist 79, 51-75.

Hamblin, C. (1969) "Starting and Stopping," The Monist 53, 410-25.

- (1971) "Instants and Intervals," Studium Generale 24, 127-34.

Hayes, P. J. (1985) "Naive Physics I: Ontology for Liquids," in J. R. Hobbs and R. C. Moore (eds.), Formal Theories of the Commonsense World, Norwood: Ablex, pp. 71-107.

Hestevold, H. S. (1986) "Boundaries, Surfaces, and Continuous Wholes," Southern Journal of Philosophy 24, 235-45.

Jackendoff, R. (1991) "Parts and Boundaries," Cognition 41, 9-45.

Kamp, H. (1979) "Events, Instants, and Temporal Reference," in R. Bäuerle, U. Egli, and A. von Stechow (eds.), Semantics from Different Points of View, Berlin/Heidelberg: Springer-Verlag, pp. 376-417.

Kline, A. D., and Matheson, C. A. (1987) “The Logical Impossibility of Collision," Philosophy 62, 509-15.

Kuratowski, C. (1922) "Sur l'opération A de l'Analysis Situs," Fundamenta Mathematicae 3, 182-99.

Leonardo da Vinci (1478/1518), I manoscritti e i disegni di Leonardo da Vinci, 4 vols., Roma: Danesi, 1923/1930 (Selected Eng. trans. ed. by E. MacCurdy in The Notebooks of Leonardo da Vinci, London: Reynal and Hitchock, 1938; reprinted by G. Braziller, 1958).

Lewis, D. K. (1991) Parts of Classes, Oxford: Basil Blackwell.

Lowe, V. (1953) "Professor Goodman's Concept of an Individual," Philosophical Review 62, 117-26.

Menger, K. (1940) “Topology Without Points,” Rice Institute Pamphlets 27, 80-107.

Newton-Smith, W. H. (1980) The Structure of Time, London/Boston/Henley: Routledge \& Kegan Paul. 
Nicod, J. (1924) La geometrie dans le monde sensible, Paris: Alcan (Eng. trans. by J. Bell, "Geometry in the Sensible World," in J. Nicod, Geometry and Induction, ed. by R. F. Harrod, London: Routledge \& Kegan Paul, 1970, pp. 3-155).

Peirce, C. S. (1893) "The Logic of Quantity," in Collected Papers of Charles Sanders Peirce, Vol. IV, ed. by C. Hartshorne and P. Weiss, Cambridge, MA: Harvard University Press, 1933.

Pianesi, F., and Varzi A. C. (1994) “The Mereo-Topology of Event Structures," in P. Dekker and M. Stokhof (eds.), Proceedings of the 9th Amsterdam Colloquium, Amsterdam: Institute for Logic, Language and Computation, pp. 527-46.

- (1996a) "Events, Topology, and Temporal Relations," The Monist, 79, 89-116.

- (1996b) "Refining Temporal Reference in Event Structures," Notre Dame Journal of Formal Logic 37, 71-83.

Price, H. H. (1932) Perception, London: Methuen.

Quine, W. V. O. (1985) "Events and Reification," in E. LePore and B. P. McLaughlin (eds.), Actions and Events. Perspectives in the Philosophy of Donald Davidson, Oxford: Blackwell, pp. 162-71.

Randell, D. A., and Cohn, A. G. (1989) "Modelling Topological and Metrical Properties in Physical Processes," in R. J. Brachman, H. J. Levesque, and R. Reiter (eds.), Principles of Knowledge Representation and Reasoning. Proceedings of the First International Conference, Los Altos, CA: Morgan Kaufmann, pp. 357-68.

Randell, D. A., Cui, Z., and Cohn, A. G. (1992a) "An Interval Logic of Space Based on 'Connection'," in B. Neumann (ed.), Proceedings of the 10th European Conference on Artificial Intelligence, Chichester: John Wiley \& Sons, pp. 394-98.

- (1992b) "A Spatial Logic Based on Regions and Connection," in B. Nebel, C. Rich, and W. Swartout (eds.), Principles of Knowledge Representation and Reasoning. Proceedings of the Third International Conference, Los Altos, CA: Morgan Kaufmann, pp. 165-76.

Rescher, N. (1955) "Axioms for the Part Relation," Philosophical Studies 6, 8-11.

Russell, B. A. W. (1914) Our Knowledge of the External World, London: Allen and Unwin.

- (1927) The Analysis of Matter, London: Allen and Unwin.

Sainsbury, R. M. (1995) "Why the World Cannot Be Vague," Southern Journal of Philosophy 33 (Supplement), 63-81.

Simons, P. M. (1987) Parts. A Study in Ontology, Oxford: Clarendon Press.

- (1991) "Faces, Boundaries, and Thin Layers," in A. P. Martinich and M. J. White (eds.), Certainty and Surface in Epistemology and Philosophical Method. Essays in Honor of Avrum Stroll, Lewiston/Queenston/Lampeter: Edwin Mellen Press, pp. 87-99.

Smith, B. (1993) "Ontology and the Logistic Analysis of Reality,” in N. Guarino and R. Poli (eds.), International Workshop on Formal Ontology in Conceptual Analysis and Knowledge Representation, Padova: Ladseb-CNR, pp. 51-68.

— (1994) "Fiat Objects," in N. Guarino, S. Pribbenow, and L. Vieu (eds.), Parts and Wholes: Conceptual Part-Whole Relations and Formal Mereology. Proceedings of 
the ECAI94 Workshop, Amsterdam: European Coordinating Commettee for Artificial Intelligence, pp. 15-23.

- (1995a) "Zur Kognition räumlicher Grenzen: Eine mereotopologische Untersuchung," Kognitionswissenschaft 4/4, 177-84.

- (1995b) "On Drawing Lines on a Map," in A. U. Frank and W. Kuhn (eds.), Spatial Information Theory, Berlin/Heidelberg: Springer-Verlag, pp. 475-84.

- (1997) "Boundaries: An Essay in Mereotopology," in L. H. Hahn (ed.), The Philosophy of Roderick Chisholm, La Salle, IL: Open Court, pp. 534-61.

Stroll, A. (1979) "Two concepts of surfaces," Midwest Studies in Philosophy, 4, 277-91.

— (1985) "Faces," Inquiry 28, 177-94.

- (1988) Surfaces, Minneapolis: University of Minnesota Press.

Tarski, A. (1929) "Les fondements de la géométrie des corps," Ksie ga Pamia tkowa Pierwszkego Polskiego Zjazdu Matematycznego, suppl. to Annales de la Société Polonaise de Mathématique 7, 29-33 (Eng. trans. by J. H. Woodger, "Foundations of the Geometry of Solids," in A. Tarski, Logics, Semantics, Metamathematics, Papers from 1923 to 1938, Oxford: Clarendon Press, 1956, pp. 24-29).

Tye, M. (1990) "Vague Objects," Mind 99, 535-57.

Van Inwagen, P. (1987) "When Are Objects Parts?," Philosophical Perspectives 1, 21-47.

Varzi, A. C. (1994) "On the Boundary Between Mereology and Topology," in R. Casati, B. Smith, and G. White (eds.), Philosophy and the Cognitive Sciences, Vienna: Hölder-Pichler-Tempsky, pp. 419-38.

- (1996a) "Parts, Wholes, and Part-Whole Relations: The Prospects of Mereotopology," Data and Knowledge Engineering 20, 259-86.

- (1996b) "Reasoning about Space: The Hole Story," Logic and Logical Philosophy 4, 3-39.

Vendler, Z. (1957) "Verbs and Times," Philosophical Review 66, 143-60.

Vieu, L. (1991) Sémantique des relations spatiales et inférences spatio-temporelles: Une contribution à l'étude des structures formelles de l'espace en Langage Naturel, Université Paul Sabatier de Toulouse: PhD Thesis.

Walker, A. G. (1947) "Durées et instants," Revue Scientifique 85, 131-34.

Whitehead, A. N. (1916) "La théorie relationniste de l'espace," Revue de Métaphysique et de Morale 23, 423-54 (Eng. trans. by P. J. Hurley, "The Relational Theory of Space," Philosophy Research Archives 5, 1979, 712-41).

- (1919) An Enquiry Concerning the Principles of Human Knowledge, Cambridge: Cambridge University Press.

- (1929) Process and Reality. An Essay in Cosmology, New York: Macmillan.

Zarycki, M. (1927) "Quelques notions fondamentales de l'Analysis Situs du point de vue de l'Algèbre de la Logique," Fundamenta Mathematicae 9, 3-15.

Zimmerman, D. W. (1996a) "Indivisible Parts and Extended Objects: Some Philosophical Episodes from Topology's Prehistory," The Monist 79, 148-80.

— (1996b) "Could Extended Objects Be Made Out of Simple Parts?," Philosophy and Phenomenological Research 56, 1-29. 